\title{
LA NORMA INFORMAL DE EMPLEO Y EL DETERIORO DE LA CONDICIÓN DE CIUDADANÍA El caso de la industria del calzado en Elda, Alicante
}

\author{
INFORMAL NORM OF EMPLOYMENT AND THE EROSION OF \\ CITIZENSHIP STATUS
}

The case of shoe industry in Elda, Alicante

Carlos de Castro Pericacho c.decastro@uam.es

Universidad Autónoma de Madrid. España.

María Arnal Sarasa m.arnal@cps.ucm.es

Universidad Complutense de Madrid. España.

Arturo Lahera SÁnchez alaheras@cps.ucm.es

Universidad Complutense de Madrid. España.

\begin{abstract}
RESUMEN
Desde finales de los años setenta numerosos sectores de diversas regiones geográficas han desarrollado una estrategia integral de reducción de costes para mantener su posición competitiva en las redes de la economía global. Uno de los puntos que han incluido estas estrategias de desarrollo ha sido la flexibilización de las condiciones de trabajo. En muchas ocasiones, llevando al extremo su propia lógica, la flexibilización ha conducido a una informalización generalizada de la actividad económica y del empleo como estrategia de competitividad. La extensión de la informalidad y la temporalidad del empleo en un sector no solo implica en sí misma el deterioro de los derechos laborales sino que además impide acceder a otro tipo de derechos socioeconómicos (prestación por desempleo, jubilación, sanidad; entre otros) con lo que se produce un deterioro de la condición de ciudadanía. Este artículo propone describir los principales rasgos de la norma informal de empleo que se ha configurado en el sector del calzado para indicar que tales condiciones de trabajo representan, por sí mismas, un deterioro de la condición de ciudadanía. El artículo se basa en una investigación del sector del calzado en Elda, Alicante (España).
\end{abstract}

Palabras Clave

Ciudadanía; Economía informal; Empleo informal; Norma de empleo; Norma informal del empleo.

\section{Abstract}

Since the late seventies many economic sectors from different geographic regions have developed a comprehensive strategy to reduce costs in order to stay competitive in the global economy networks. Flexibility of working conditions is one of the points that these development strategies have included over the years. In many cases, leading to an extreme their own logic, flexibility has led to a widespread informalisation of economic activity and of employment as a competitive strategy. The spread of informality and temporary employment in a sector not only imply itself the deterioration of labor rights but also prevents access to other socioeconomic rights (unemployment benefit, retirement, health, etc.) and thus the deterioration in the condition of citizenship. This article aims to describe the main features of the informal norm of employment that has been set in the footwear sector to indicate that such working conditions represent a deterioration of the condition of citizenship. The article is based on research in the footwear industry in Elda, Alicante (Spain).

\section{KEYWORDS}

Citizenship; Employment Norm; Informal Economy; Informal Norm of Employment; Informal Work. 


\section{INTRODUCCIÓN}

El sector del calzado en España se concentra principalmente en la Comunidad Valenciana (el $64 \%$ de la producción del sector, el $65,36 \%$ de las empresas de calzado y el $62,28 \%$ del empleo en el sector) y, dentro de la Comunidad Valenciana, Elda es uno de los municipios más especializados en el sector junto con Elche (Ybarra, San Miguel et al. 2004). Según la Federación de la Industria Española del Calzado (FICE), desde 2001 el sector del calzado ha registrado una dramática caída de la actividad y del empleo a nivel nacional, aunque parece haberse amortiguado desde el año 2010. El valor de la producción ha descendido casi un 50\%, pasando de 3157 millones de euros en 2001 a 1572 millones de euros en 2011. El empleo también ha sufrido una fuerte caída, del $50 \%$ aproximadamente, pasando de 46.309 empleados en 2002 a 22.896 empleados en $2011^{1}$. A pesar de ello, Elda sigue siendo una importante ciudad industrial donde el $51,3 \%$ del empleo se concentra en el sector industrial (y el 83,6\% del sector industrial en el calzado) y el $41,3 \%$ en el sector servicios, lo cual explica la fuerte identificación de la ciudad con el calzado, tanto dentro como fuera de Elda (Arnal, De Castro et al. 2012).

El recurso generalizado de las empresas a la estrategia de competencia por costes, como vía de salida a la profunda crisis que el sector atravesó a finales de los setenta, ha dotado de unos rasgos propios a la industria eldense del calzado: la fragmentación del tejido productivo en pequeñas y medianas empresas ${ }^{2}$ y la enorme proporción de economía y de empleo sumergidos (Ybarra, San Miguel et al. 2004; Ybarra, Giner Pérez et al. 2002; Cachón 2005).

Entre las consecuencias de la informalización del sector sobre las relaciones laborales está la extensión de contrataciones irregulares y la contratación temporal semilegal. Además, este deterioro de las condiciones de trabajo se ha traducido, entre otras cosas, en un déficit permanente de mano de obra especializada, en un descrédito de la profesión zapatera entre los jóvenes y, en consecuencia, en su huida del sector, en una pérdida de confianza en el futuro del sector y en la ruptura de las relaciones de confianza entre trabajadores y empresarios (Ybarra, San Miguel et al. 2004; Cachón 2005; San Miguel 2000).

El caso de Elda puede inscribirse dentro de la tendencia general hacia la flexibilidad del empleo iniciada en los años setenta en los países más desarrollados (Bosch, Lehndorff et al. 2009; Koch 2006; Standing 2009; Miguélez y Prieto 2009). Prieto (2002) ha caracterizado esa tendencia como la transición desde una norma salarial del empleo a una norma flexible de empleo. Según este esquema, en la norma salarial, predominante desde finales de los cuarenta hasta mediados de los setenta, el empleo era seguro

\footnotetext{
${ }^{1}$ Los datos proceden de los anuarios del calzado de la FICE de los años 2007, 2009 y 2011.

${ }^{2}$ En 2009 el $78,23 \%$ de las empresas del calzado tenían menos de 49 empleados y el $36,3 \%$ tenían entre 3 y 5 trabajadores. Véase en www.fice.es.
} 
y estable, las jornadas eran regulares y el salario variaba según la cualificación y se actualizaba según el coste de la vida. Por su parte, en la norma flexible, predominante desde finales de los setenta, el empleo es inseguro e inestable, las jornadas son más largas e irregulares, los salarios tienden a ser más bajos y variables. Aunque pueda tratarse de una caracterización muy esquemática, lo que se pretende enfatizar es que estos rasgos son la expresión de una transformación de la regulación social y política del empleo (Prieto, 2002). Lo más interesante del concepto de norma social de empleo hace referencia a su dimensión política, esto es, las características singulares de los empleos no importan en sí mismas sino en la medida en que remiten a una forma de delimitar los derechos laborales y los derechos sociales. Así pues, en cualquier norma social de empleo, la regulación social y política contribuye a configurar la condición política del trabajo y, por tanto, la propia condición de ciudadanía. En este sentido, la tendencia general hacia la flexibilidad indicaría que la participación en el trabajo asalariado ha perdido relevancia como fuente primordial de acceso a los derechos políticos, sociales y económicos y que, en consecuencia, estaría dando lugar a un deterioro de la condición de la ciudadanía (Alonso 1999; 2007).

En este artículo se sostiene que dicho deterioro de la condición de ciudadanía vendría propiciado por una doble vía: por un lado, a causa de una práctica "desdemocratizadora" (Tilly 2010) que afecta al mercado laboral en general y que se caracteriza por el sistemático retroceso en la legislación que regula los derechos laborales y sociales de los trabajadores (Harvey 2007; Pisarello 2011); y por otro lado, por unas prácticas laborales en las que el marco legislativo vigente es sistemáticamente vulnerado. Ambos procesos confluyen en el caso analizado, pero sin duda el sector del calzado en Elda destaca por la incidencia de esta segunda opción.

La "desdemocratización" se refiere a la subordinación de los procedimientos democráticos de las instituciones estatales y a la orientación de sus formas de intervención (Ingham 2010) a las necesidades de la economía, del crecimiento y de la competitividad. Más en general, se refiere a la atenuación del contenido democrático de las constituciones de los Estados (Pisarello 2011). En el ámbito del trabajo, la desdemocratización de las relaciones laborales está relacionada con las numerosas reformas laborales que se han realizado en los países desarrollados en las últimas décadas (Doogan 2009) con el objetivo de eliminar o "flexibilizar" todo el conjunto de derechos sociales y laborales que configuraban el modelo de ciudadanía social de la Posguerra (Alonso 1999) y que habían "desmercantilizado" parcialmente el trabajo, aun cuando eran limitadamente compatibles con el objetivo de competitividad en un mercado global. El caso de España representa un buen ejemplo de ello, tanto por el espíritu como por la cantidad de reformas laborales — cincuenta y tres - que se han realizado desde 1984 hasta la actualidad (Aragón 2012).

No obstante, el caso de Elda no representa un caso paradigmático de la flexibilización, sino que más bien pone de manifiesto que esa tendencia hacia la flexibilidad no es homogénea y que presenta variaciones significativas en cada país y en cada sector (Fevre 2007; Doogan 2009). La trayectoria de flexibilización que ha seguido el sector del 
calzado eldense ha sido muy peculiar y va un paso más allá, en la medida en que se ha basado en una profunda informalización del empleo. De ahí, que aquí se sostenga que el resultado de esa específica trayectoria de flexibilización haya sido la constitución de una "norma informal" de empleo que ha deteriorado la condición de ciudadanía. Para dar cuenta de ello, el resto del artículo realizará una descripción detallada y actual de las principales características del empleo en el sector del calzado en Elda destacando la dimensión política de cada una ellas.

\section{Metodología}

El objetivo de este artículo, a saber, analizar el deterioro de la condición de ciudadanía asociado a la generalización actual de la informalización del empleo en el sector del calzado en Elda ${ }^{3}$, puede llevarse a cabo de muchas maneras. Hay al menos dos razones por las que aquí se opta por un enfoque metodológico cualitativo. En primer lugar, la tendencia hacia el ocultamiento de la actividad (Portes, Castells et al. 1989; Benton 1990; Ybarra, San Miguel et al. 2004) y la elevada proporción de la informalidad del empleo en el sector del calzado, que según las estimaciones de Ybarra, San Miguel et al. (2004) estaría próxima al 50\%, obliga a hacer un uso muy "matizado" de las fuentes secundarias estadísticas disponibles, tal y como recomienda la propia patronal del sector ${ }^{4}$. Aquí se han utilizado las fuentes secundarias estadísticas junto con varias técnicas cualitativas (entrevistas, grupos de discusión y observación participante) con el fin de describir la situación en la que se encuentra el sector en la actualidad, aunque también se ofrece alguna información sobre los antecedentes históricos más inmediatos.

La segunda razón tiene que ver con la condición de la ciudadanía. Aquí se sostiene que dicha condición, en general, y la dimensión política del trabajo, en particular, están vinculadas con una definición colectiva y compartida de la situación. La aproximación cualitativa es imprescindible para poder acceder a esos discursos compartidos. En ellos podemos ver de qué manera las experiencias vitales de todos los trabajadores entrevistados están atravesadas por un discurso que hace referencia a la degradación del empleo en el sector y a la pérdida de derechos asociados a ella. Esos discursos nos permiten identificar las limitaciones de los derechos laborales y sociales a las que con mayor frecuencia se enfrentan los trabajadores del calzado. Nos ofrecen por tanto un

\footnotetext{
${ }^{3}$ Este trabajo forma parte del proyecto europeo "SPHERE" (Space, Place and the Historical and contemporary articulations of regional, national and european identities through work and community in areas under going economic restructuring and regeneration), financiado dentro del $7 .^{\circ}$ Programa Marco de la U.E. (SSH85.2.01), desarrollado entre 2008 y 2011, y en el que el equipo español se ocupó de indagar en dos ciudades industriales en crisis: Elda (sector del calzado) y Alcoy (textil). El trabajo de campo se realizó entre marzo de 2009 y agosto de 2010.

${ }^{4}$ Veáse el informe de la FICE del año 2011 (2011:6).
} 
mapa muy completo y preciso del deterioro de la condición de ciudadanía en un sector concreto y en una región específica.

Se realizaron dos tipos de entrevistas distintas: 9 de ellas a expertos, y 14 a distintos trabajadores con alguna vinculación directa o indirecta con el calzado. Entre los entrevistados seleccionados por su condición de expertos, unos lo han sido por su estudio y conocimiento del tema desde el ámbito académico local (profesores e investigadores); otros por haber vivido desde las instituciones el cambio, desempeñando un papel más activo y destacado en distintos ámbitos de la sociedad eldense, tales como agentes sociales (empresarios y sindicatos), representantes de diversas asociaciones culturales (comparsas), religiosas (párroco local) y políticas (personal de la Administración Local: Ayuntamiento). En las entrevistas a trabajadores de Elda, además del sexo ( 7 entrevistas a mujeres y 7 a hombres) y la edad ( 3 a jóvenes, 3 a adultos y 1 a jubilados), se tuvo en cuenta el sector de ocupación: mayoritariamente pertenecientes a la industria del calzado, pero se buscó que también hubiera representación de otros sectores, manuales o de servicios. Las entrevistas eran abiertas, con un guion de conducción adaptado a cada entrevistado, pero con temas comunes sobre cuestiones centrales como: los cambios en la situación socioeconómica del sector (y las familias); las transformaciones en las condiciones de trabajo y en el empleo; los cambios en el consumo, ocio y tiempo libre, precedido, cuando era pertinente, de un breve relato autobiográfico, a modo de presentación, de la persona entrevistada.

También se realizaron dos grupos de discusión para observar los cambios en la percepción e imagen del sector entre los jóvenes de ambos sexos de entre 20 y 35 años. Ambos grupos se centraron en el calzado, a pesar de que uno de ellos era un grupo mixto, integrado por hombres y mujeres ocupados en otras actividades, pero buenos conocedores del sector, con y sin familiares vinculados al calzado y con educación secundaria o universitaria; el otro lo formaron varones trabajadores o extrabajadores del sector con nivel de estudios primarios y secundarios.

Por último se ha tenido en cuenta la observación directa con el propósito de contrastar información y tomar referencias de primera mano sobre desigualdades sociales, distribución espacial en el territorio, trazado urbanístico, patrimonio industrial y cultural, distribución de infraestructuras, fábricas, talleres, asociaciones, etc. Estas tres fuentes de información cualitativa se han articulado con el fin de tener una visión lo más estereoscópica posible y contextual de la situación del sector y procesos implicados en él.

\section{El EMPLEO En Elda. Hacia unA NORMa informal de EMPLEO EN EL SECTOR DEL CALZADO}

Sassen (2007) ha señalado que la informalización del empleo está ligada a la reestructuración global de la economía y a la nueva división internacional del trabajo. Además esta autora sostiene que se ha producido una polarización económica entre los sectores de actividad. Los servicios especializados y, sobre todo, los financieros se estarían 
imponiendo al resto de los sectores de servicios de escaso valor agregado y al sector industrial gracias a sus rentabilidades más altas. La presencia de una red de empresas con capacidad de generar beneficios exorbitantes estaría contribuyendo a elevar el precio de los espacios comerciales y del resto de los servicios auxiliares. En un contexto así se hace muy precaria la supervivencia de empresas de menor tamaño. Lo paradójico es que, aunque la demanda de sus bienes y servicios siga existiendo e incluso vaya en aumento, estas pequeñas y medianas empresas no pueden competir a menos que funcionen informalmente. En otras palabras, la informalización de la actividad económica constituye un elemento estructural de la economía global. El caso de Elda ilustra este extremo puesto que la proliferación de talleres clandestinos y de aparadoras que trabajan desde casa forman parte de una estrategia de competencia del sector para ser "viable" en un mercado global.

Resulta muy complicado distinguir nítidamente entre actividades formales y actividades informales (Mingione 1994). Las diferencias entre la economía formal e informal no radican en la naturaleza del producto o del servicio final sino en la forma en que se produce y se distribuye. La informalización suele asociarse al incumplimiento de las normas legales para la realización de actividades económicas. A pesar de su aparente sencillez, esta distinción no oculta la existencia de solapamientos entre las actividades formales e informales (Portes y Haller 2005). Así, por un lado, todos los bienes y servicios legales suelen producirse en diferentes etapas y puede ocurrir que algunas de esas etapas no respeten la regulación legal mientras que otras sí lo hagan. Por otro lado, pueden cumplirse algunas de las normativas (así, la fiscal) y no cumplir otras (por ejemplo, la laboral). Y por último, pueden cumplirse las normativas "a medias" (verbigracia, tener un plantilla en la que solo la mitad tiene contrato o cotizar a la Seguridad Social por una cantidad menor a la real). En realidad, lo común es que en las actividades económicas coexistan fases formales e informales. De hecho, en uno de los casos más radicales de economía sumergida, como es el caso de Elda, los diferentes agentes (empresarios, intermediarios y trabajadores) no incumplen indiscriminadamente todas las normas sino que solo respetan aquellas normas que pueden reportarles algún beneficio.

\section{ANTECEDENTES HISTÓRICOS}

La informalización del sector del calzado en esta ciudad está estrechamente vinculada con la manera en que se resolvió la crisis de los años setenta. Desde esta década algunas grandes empresas estadounidenses del calzado dejaron de producir en su país para convertirse en comercializadoras y realizar la producción en varias regiones periféricas (Nash 1989), siendo el levante español una de ellas. Estas empresas controlaban el diseño, las redes comerciales del mercado estadounidense y coordinaban la producción en las regiones en las que se habían instalado. La industria del calzado eldense quedaba así apartada de la fase más creativa y comercial del proceso productivo y se dedicaba tan solo a la elaboración del producto. La producción de grandes cantidades 
de zapatos estandarizados provocó la aparición de empresas más grandes y una mayor mecanización de los procesos de elaboración. El desarrollo de la industria se había basado en los reducidos costes de una mano de obra que recurría al calzado como complemento de la actividad agrícola y que acumulaba un buen conocimiento del oficio gracias a la tradición zapatera de la comarca. El crecimiento del sector fue tan espectacular que atrajo una gran cantidad de mano de obra procedente de zonas rurales cercanas (Albacete, Murcia y de la provincia de Valencia). En consecuencia, también empezó a extenderse significativamente el trabajo asalariado y comenzaron a emerger algunos conflictos laborales típicos. Las relaciones laborales que surgieron durante esa breve época de producción en masa fueron lo más parecido a la norma salarial de empleo, dada la homogeneidad de las condiciones de trabajo (Miranda 2001).

Esta situación empezó a cambiar rápidamente a partir de la crisis de mediados de los años setenta. Elda sufrió especialmente aquella crisis debido a la huida de las grandes empresas norteamericanas de distribución hacia los entonces emergentes países asiáticos, en busca de los menores costes productivos. Como dicen algunos expertos del sector, los eldenses fueron los primeros chinos de los americanos (Valero 1992; Miranda 2001).

La respuesta de las empresas locales a esta situación consistió en desplegar una estrategia basada en la reducción de costes que a la larga ha dado lugar a un progresivo deterioro de las condiciones de trabajo. Sin embargo, lo verdaderamente significativo no es el recurso a la informalidad, puesto que es algo que se ha realizado esporádicamente desde el inicio del sector a finales del siglo XIX, sino que desde ese momento se empezará a utilizar como estrategia de competitividad (Ybarra 2000).

Tras una larga crisis, el sector comenzó una leve recuperación a mediados de los ochenta gracias al ingreso de España en la U.E, en 1986. Esto permitió alcanzar el mercado europeo y mejorar la producción y las exportaciones pero no logró eliminar la estrategia de la competencia basada en los costes, sino más bien consolidarla y convertirla en un rasgo estructural. Hasta principios de los años noventa el sector mantuvo una tímida tendencia al alza, pero será durante el periodo 1993-2000 cuando la industria eldense del calzado atraviese una nueva época dorada (Cachón 2005) en la que se profundizará su informalidad, tanto en la producción como en el empleo. Desde el año 2000 hasta la actualidad se ha producido una lenta pero persistente caída de la actividad y del empleo en el sector debido en parte a que la industria china del calzado ha mejorado la cifra de producción y de exportaciones en toda la gama de productos, incluso en los de calidad media 5 . La crisis financiera iniciada en 2008 no ha hecho sino acentuar esa tendencia, en parte por la caída de las ventas en el mercado nacional y en parte por las dificultades de acceso al crédito, lo que ha supuesto el cierre de numerosas empresas (reducción del $23,52 \%$ de las empresas y del $21,20 \%$ del empleo en tres años, de 2008-2011, FICE $2011)^{6}$ y la profundización, aún mayor, de la estrategia de reducción de costes.

\footnotetext{
${ }^{5}$ www.fice.es

${ }^{6}$ Alguno de estos cierres tuvo un impacto social y mediático importante, como fue el cierre en septiembre
} 


\section{ESTRUCTURA EMPRESARIAL DEL SECTOR: FÁBRICAS DISPERSAS E INVISIBLES}

Desde los años setenta, la presión de la competencia en los mercados internacionales ha impulsado una tendencia hacia la flexibilización de la organización de la producción pasando de un modelo fordista de producción a gran escala a un modelo de "especialización flexible" basado en la descentralización de la producción y en la consecuente subcontratación a otras empresas ${ }^{7}$. En el caso de Elda, la extensión de este modelo ha dado lugar a la proliferación de una tupida red de subcontratas dispersas por toda la comarca por las que se distribuyen las numerosas fases de fabricación del calzado, concentrándose en la empresa matriz las áreas de diseño y comercialización (Ybarra 2000). Las diferentes fases de la producción (diseño, cortado, rebajado, doblado, aparado, montaje y almacenaje) se realizan mayoritariamente fuera de la fábrica, al contrario de lo que era habitual en los años sesenta. Aunque es posible encontrar en la actualidad alguna fábrica que realice dos o tres fases, lo habitual es que cada taller se especialice en una fase. Las fases que se suelen externalizar son la del cortado y la del aparado, y la externalización suele realizarse de varias formas: subcontratación a talleres legales 0 ilegales, o mediante el trabajo a domicilio, formal o informal. Y es aquí donde se fraguan las relaciones laborales más específicas del sector, marcadas por la tendencia a aplicar interpretaciones forzadas de la legislación vigente, cuando no a evitar su cumplimiento.

Se trata de un tipo de descentralización en el que las empresas subcontratadas se encuentran subordinadas a la estrategia comercial de las empresas matrices, ya sean estas marcas o comercializadoras.

Pero si hay algo que permite dar cuenta de la naturaleza estructural de la informalidad del sector es la estrategia del falso cierre de empresas o "persianazo", que tiene su origen en la dramática reconversión industrial que se realizó en Elda a principios de los ochenta, pero que se perpetúa hasta la fecha, y que iba acompañada del impago de cotizaciones a la Seguridad Social y de impuestos, de estrategias fraudulentas de contratación para beneficiarse de las bonificaciones para la contratación, etc. (Benton 1990; Ybarra 2000). Esta estrategia, y las restantes que veremos a lo largo del artículo continúan hasta la actualidad.

La estrategia del cierre falso de empresas otorga al sector un dinamismo espectacular y ha originado una dinámica de creación y desaparición de empresas con una lógica financiera propia (Ybarra 2000). Son numerosas las referencias de los entrevistados al constante cambio de empresa:

de 2010 de la fábrica Kurhapies después de 64 años de existencia. Esta fábrica, una de las más emblemáticas de Elda, refleja las distintas fases por las que ha pasado el sector a lo largo del s. XX.

${ }^{7}$ Sobre la subcontratación, véase Allison Davis-Blake (2009) y Stewart et al. (2009). 
"[...] además mucho cambio de empresa [...] Además, aunque tú estés en la misma empresa, no estás en la misma empresa nunca, es otro nombre [...] Cobras finiquitos que firmas que cobras y no los cobras, todo así...". (Mujer, 57 años, trabajadora del calzado jubilada).

La declaración fraudulenta de insolvencia por parte de la empresa permite dejar impagados los costes de seguridad social, los impuestos, y las indemnizaciones de los trabajadores. Los trabajadores no suelen ser demasiado críticos con esta estrategia puesto que ellos suelen cobrar las deudas salariales del Fogasa (Fondo de Garantía Salarial). Por su parte, los proveedores y los bancos son los únicos agentes que cobran en su totalidad las deudas. De hecho, para mantener esta estrategia de apertura y cierre resulta fundamental hacer frente a las deudas bancarias y de proveedores (Benton 1990; Ybarra 2000). En su conjunto, una empresa con problemas puede cerrar un día y abrir al siguiente con la misma maquinaria, puesto que esta nunca está a nombre de la empresa, y con una parte reducida de los trabajadores, aprovechando estos cierres para deshacerse de los trabajadores "molestos", y de paso eliminan la antigüedad de la plantilla:

"[...] Yo tuve una experiencia. Cerró la fábrica, estaba 12 años trabajando allí. Cerró y a la semana siguiente abrió, haciendo el mismo tipo de faena, todo igual. Mandaron a la inspección, fue la inspección, le pilló con la ropa de trabajo, de la marca antigua, y no les hizo nada. Nada. Y te quedas con cara de aquí qué pasa. Y no me readmitieron ni nada. Fui a Fogasa, me pagó Fogasa y fuera...". (Grupo hombres jóvenes trabajadores del calzado).

La combinación de la estrategia de la subcontratación con la del "persianazo" durante más de treinta años ha provocado que la informalización se haya constituido en rasgo estructural del sector y, más importante, ha permitido aflorar una cultura laboral de la informalidad compartida, aunque de forma discreta, por empresarios, trabajadores e instituciones, y considerada como la única vía de supervivencia del sector en el contexto de una economía global crecientemente competitiva.

Del mismo modo, la combinación de estas dos estrategias ha dado lugar a la configuración de una "norma informal" de empleo en la industria del calzado eldense cuyos rasgos específicos se muestran a continuación.

\section{Reducción de LA ASALARIZACIÓN}

La estrategia de la subcontratación ha provocado una leve aunque significativa reducción de la asalarización del sector debido a que parte de los trabajadores se han convertido, voluntariamente o forzados por las empresas en las que previamente estaban contratados, en pequeños empresarios, abriendo talleres semi-legales o directamente clandesti- 
nos. No obstante, en la mayoría de los casos, se trata de figuras de falsos autónomos o de "falsos empresarios" en la medida en que casi toda su actividad se realiza para una sola empresa. De hecho, durante estos últimos años de crisis las únicas empresas del cuero y del calzado que han crecido en la Comunidad Valenciana son las empresas "sin asalariados" (que han pasado de 903 en 2008 a 1045 en 2012) mientras que todas las demás retroceden (en total se ha pasado de 3006 en 2008 a 2620 en 2012) ${ }^{8}$.

\section{OCULTACIÓN DE LA ACTIVIDAD}

La informalización o la ocultación de la actividad es la forma de externalización más utilizada y otra de las razones de la disminución de los asalariados. Las estimaciones de Ybarra, San Miguel et al. (2004) cifran el volumen de la producción sumergida en cerca de un $50 \%$ y en un $45 \%$ para el empleo sumergido. Eufemísticamente hablan de tareas "de la calle", la mayoría del aparado y el cortado:

"[...] la encargada es la que se encarga de revisar las faenas dentro de la calle para que todo vaya bien. Si ve alguna falta o alguna cosa rota para volverlo a poner o mandarlo a cortar. Lo primero de todo es el cortado. Le llegan las pieles. Ahora solo está [dentro de la empresa] el encargado solamente que da faena a la calle. Los cortadores todos están en la calle .Y se encarga de dar lo que son....como si dijéramos el patrón ¿vale? Los patrones de los zapatos entonces se encarga de distribuirlos y los corten. Luego ya viene a la empresa y la encargada de aparar les da las aparadoras. Luego cuando a ellas le llegan es cuando lo revisan". (Mujer, 32 años, encargada taller de calzado).

Las formas de ocultamiento o de informalización más extendidas comprenden las irregularidades en la contratación; la realización de horas extra en empresas legalmente constituidas; o la ausencia de todo tipo de vínculo contractual en empresas completamente sumergidas, sin existencia legal, que trabajan para otras empresas que son legales. Un entrevistado decía, entre risas, que cuando van los inspectores a los polígonos industriales de la zona hay la misma gente en la calle que un día de fiesta en las principales avenidas:

"¿sabes por qué?, iporque vinieron inspectores y toda la gente que estaba sin contrato, sale fuera y dice, estaban los bares a reventar! (Hombre, 31 años, trabajador del calzado).

Una de las formas más extendidas de trabajo informal es la del trabajo a domicilio. El sector del calzado ha estado tradicionalmente vinculado a esta fórmula, aunque restrin-

\footnotetext{
${ }^{8}$ Instituto Nacional de Estadística: Directorio Central de Empresas.
} 
gido principalmente a la fase del aparado. Son las mujeres quienes desde sus casas realizan las tareas del aparado porque les permiten aportar ingresos al hogar mientras cuidan de los hijos. Además, se puede observar una división sexual de las fases de la producción del calzado. Las mujeres se suelen ocupar del aparado y del almacenaje y los hombres del diseño y del cortado (San Miguel 2001). Por otra parte, dentro del ámbito informal, también está la figura del intermediario comercial autónomo que se dedica a coordinar la realización de diferentes tareas, trasladando el material de un taller a otro para después colocar el producto final en alguna empresa legalmente constituida

\section{TeMPORALIDAD E INSEGURIDAD EN EL EMPLEO}

Dado el frenético ritmo de creación y desaparición de empresas, el contrato más extendido, cuando existen relaciones contractuales, es el temporal. La contratación temporal permite al empresario absorber la estacionalidad de la actividad. El contrato fijo discontinuo, que fue concebido precisamente para sectores con elevada estacionalidad, no es muy utilizado puesto que obliga a los empresarios a mantener a los mismos trabajadores, y cuando existen, los trabajadores también denuncian abusos:

"[...] para que la empresa fuese viable cambiamos a fijo-discontinuo que es un sistema de contrato que nos está llevando de mal en peor. [...] tengo los mismos derechos ahora pero en discontinuo, la única diferencia es que cuando no hay faena nos mandan al paro, no pagan la seguridad social, pero se están aprovechando bastante de la situación. [...] este año voy a trabajar muy poco,... no llega a 6 meses. [...] Pero cuando tú haces ese sacrificio de cambiar unos derechos y hay faena y dan faena a la calle para terminar antes y cuanto antes la hagas tú antes entras al paro [...]. (Hombre 53 años, trabajador del calzado).

Por otra parte, hay que destacar una práctica muy extendida en la comarca: el "contrato a rueda" (Ybarra, San Miguel et al. 2004), que constituye un uso fraudulento del contrato temporal y consiste en que un mismo contrato temporal rote entre los empleados de tal forma que, por ejemplo, un tercio de la plantilla esté trabajando con contrato, otro tercio trabaje sin contrato y otro tercio trabaje sin contrato y cobre la prestación por desempleo. Se trata, por tanto, de un régimen de informalidad de fronteras muy difusas.

"Por ejemplo si hay 20 trabajadores, son contratos rotativos cada seis meses, se te cumple el alta cada seis meses y en otras empresas te puede durar hasta cinco. Entonces siguen en la empresa pero con cinco meses de alta, o sea, siguen siendo siempre los $20 . . . Y$ eso es algo normal, normal, normal, en este pueblo. No es la primera vez que un niño de 22 o 23 años quiere comprar un piso de protección oficial y tener que pedirle que por favor le dé de alta desde el 1 de enero al 31 de Diciembre, que bueno 
que ya ha estado de baja el año entero, pero que este año lo cumpla porque si no, no va a poder acceder a las subvenciones con sus mínimos y sus máximos". (Mujer, 36 años, empresaria).

Los contratos indefinidos se concentran principalmente en las empresas antiguas, en gente de confianza o familiares y en puestos de responsabilidad y mayor cualificación. Pero después de tantos años de aplicar la estrategia del falso cierre de empresas, la contratación indefinida alcanza a una minoría de la plantilla (10-12\% según nuestros informantes ${ }^{9}$ ), estando la gran mayoría sometidos a la temporalidad y a la incertidumbre sobre su futuro laboral:

"A los 14 años te metían en una fábrica y de esa fábrica salí con 32 años, porque la cerraron... ahí sí que estaba de punta a punta cada año fija [enero a diciembre], pero la cerraron, me pagaron el despido, me pagaron todo el cierre [...].

-¿Y dónde estabas ahora, cómo era?

Estabas tres meses, a lo mejor te ponía tres meses fija y tres meses no, tres meses sí, tres meses no y luego en agosto, septiembre y octubre ya no te ponía o a veces ya decías, oye, qué no nos vamos a poner, y ya nos ponía, pero si no decías nada, la gente estaba trabajando sin contrato y sin nada". (Mujer, 47 años, aparadora).

\section{TEMPORADAS MÁS CORTAS Y JORNADAS MÁS LARGAS E INTENSAS}

La norma salarial de empleo del periodo fordista aseguraba un trabajo a tiempo completo durante todo el año, sin embargo un empleo de ese tipo, un empleo "normal", se ha convertido en un vago recuerdo en la industria del calzado de Elda. Por un lado, se trata de una actividad con un fuerte carácter estacional en el que las temporadas coinciden con los cambios de estación verano/invierno. Cada temporada de calzado es de unos 6 meses, con algunos picos de mayor actividad como en las navidades y al final de la primavera. En la actualidad los tiempos se acortan porque las temporadas comienzan más tarde, ajustándose a la lógica del "justo a tiempo" para minimizar riesgos.

"[...] se esperan al final para... según cómo van las cosas pues así. Y luego tienes que hacer 100 si te dicen en un tiempo, que en ocasiones lo que se ha hecho en 6 meses ahora se hace en 2 meses". (Mujer, 57 años, trabajadora del calzado).

${ }^{9}$ Información procedente de uno de los expertos sindicales entrevistados. 
Por otro lado, las jornadas son más largas e intensas durante los periodos de actividad. Resulta difícil determinar con exactitud la duración efectiva de las jornadas de trabajo. Un entrevistado indica las horas según el convenio:

"Bueno, el horario de convenio son 40 horas. Entonces el horario justo es de 8 a 1 y de 3 a 7 . Eso son 9 horas. 9 por 4 días 36. Más 4 del viernes por la mañana 40. Normalmente se acaba a la 1, porque como se almuerza pues esa hora por los almuerzos, pero eso es el horario justo. Pero normalmente si hay faena se pactan horas extras 0 sueldos...." (Hombre, 58 años, trabajador del calzado).

Sin embargo, hablan de jornadas de 10 horas de media, las cuales pueden aumentar durante periodos de máxima actividad, y no siempre se remuneran:

"en las empresas que ha trabajado [mi marido] por muchas horas que hagas cobras lo mismo". (Mujer, 57 años, trabajadora del calzado).

En la práctica, las jornadas se alargan todo lo que sea necesario, ya que no se suele contratar a más trabajadores para atender los picos de producción. Los entrevistados lo narran con cierta impotencia:

"empezar sí que empezábamos más 0 menos a las 8 , pero terminar no sabíamos cuándo terminábamos". (Hombre, 58 años, trabajador del calzado).

"mi marido desde las 8 de la mañana y ya no viene ni a comer, hasta las 11 o 12 de la noche. [...] hasta los sábados por la mañana, ya al medio día termina y ya el domingo descansa. [...] los viernes sale a las 7 de la tarde". (Mujer, 47 años, aparadora).

Igual o peor ocurre con las aparadoras, al trabajar en casa la jornada se alarga hasta altas horas de la noche e incluso se extiende a todo el fin de semana:

"Pues me acostaba a las 203 de la mañana preparando la faena para otro día. [...] Trabajaba todo el día. Y alguna vez hasta los sábados y los domingos". (Mujer 60 años, trabajadora del calzado).

\section{Salarios bajos Y "Creativos"}

El pago a destajo con un límite máximo es el más extendido en el sector. Los salarios se han mantenido en niveles relativamente bajos ${ }^{10}$.

\footnotetext{
${ }^{10}$ Según el Convenio Colectivo en vigor desde 1 de marzo de 2007 hasta el 28 de febrero de 2010, los sueldos oscilan entre 976,58 euros y 1509,86 euros. Véase www.fice.es.
} 
"[...] tú dices ¿estas horas me las vas a pagar?, te dicen, no es que estas horas no se pagan porque van en el sueldo, y como va a ir en el sueldo si tenemos el sueldo de la nómina nada más. Si no llegamos ni a mil euros al mes, según el mes 900 y pico, 0 1020 euros si el mes trae 31 días y si fuera de menos, es que no llegas y qué haces no merece la pena, si aquí [aparando en casa] gano 300 y pico euros a la semana igual merece la pena y sin problemas". (Mujer, 47 años, aparadora).

Las subidas salariales, o su mero mantenimiento, se han realizado principalmente por medio de la reducción de las bases de cotización; de tal forma que los salarios suelen tener dos partes: una legal, que aparece reflejada en la nómina, y otra parte no declarada. Normalmente los pagos se realizan en metálico, en sobres, nunca por medio de transferencia bancaria, para evitar dejar un rastro contable que pueda utilizarse en una eventual inspección:

"[...] sí, sí, pagan por semanas y en sobre..., me pagan en un sobre como este... 0 en el mismo de las cartas que reciben del banco, me ponen ahí mi nombre y lo cierran con una grapita aquí y me lo dan". (Hombre, 31 años, trabajador calzado).

El salario ha adquirido una estructura tan fraudulenta como compleja y creativa. No obstante, los costes salariales se han podido reducir aún más debido a que durante los periodos en los que los trabajadores no poseen un contrato temporal trabajan de manera informal para la misma empresa, de tal manera que el trabajador suma su prestación por desempleo al salario mientras que el empresario tan solo paga el salario y evita todo tipo de costes adicionales. Además, se ha constatado que en los últimos meses los empresarios han realizado una drástica reducción del salario de quienes cobran prestación. Así pues, si hasta hace poco esos trabajadores cobraban de manera fraudulenta el equivalente a casi dos salarios, ahora parece haberse extendido la práctica de mantener el salario habitual durante estos periodos descontando el coste de la prestación:

"[...] bueno, el cerrojazo lo pegó para finales de verano y volvió a abrir en otro lado pero esta vez dio de alta a dos o tres, y él como jefe. Seguían trabajando todos y la gente seguía cobrando el paro. Y lo que hizo, lo curioso de esto, lo que hizo es que le dijo a la gente, mirar... si queréis trabajar aquí, lo que vais a hacer es que, como estáis cobrando el paro, si os dan... si yo a ti te estoy pagando mil euros y el paro te va a pagar quinientos, pues tú vas a venir la jornada entera, y yo te voy a pagar hasta mil euros, o sea, te voy a dar quinientos, te voy a dar quinientos por que vengas toda la jornada, porque como también estás cobrando el paro". (Hombre, 31 años, trabajador del calzado).

Por otra parte, puede identificarse una estratificación de los salarios según la ocupación. Hay que señalar que todas las fases del calzado, salvo quizá el almacenaje, requieren una mano de obra con una cualificación muy específica. En las fases de diseño, cortado y montaje, que son ocupaciones masculinizadas casi en su totalidad, los 
salarios son más elevados puesto que reconocen una cualificación técnica asociada a tales tareas.

Por su parte, el aparado, que casi en su totalidad es realizado por mujeres a domicilio, a pesar de requerir igualmente una especialización muy elevada, no goza del mismo reconocimiento salarial. E igual ocurre con el trabajo de acabado del producto dentro de las fábricas. Una entrevistada, encargada de parte del proceso de producción en una empresa de un familiar, realizaba varios trabajos en la empresa y reconocía:

"No tengo tiempo ni para respirar... De 420 [euros] o 430 no bajo, la quincena. A no ser que hagamos una birria de pares que... hombre si hacemos 700 pares no me va a pagar 400 euros [la quincena]". (Mujer, 32 años, encargada de taller de zapatos).

Esto puede deberse a que las mujeres aprenden el oficio de aparadora o de acabado (brillo, adornos, limpiado del zapato, etc...) de manera informal a través de las redes familiares y vecinales. Estas cualificaciones no son reconocidas formalmente puesto que se asocia a tareas supuestamente femeninas (coser, ordenar, limpiar). Esta naturalización de las tareas contribuye a una importante desvalorización del trabajo y, por tanto, a una importante reducción salarial:

"No ha estado nunca muy bien pagado. $Y$ tampoco podías decir que te subieran algo porque se lo daban a otra. Te tenías que callar". (Mujer, 60 años, trabajadora del calzado).

\section{SALUd, SEguridad E higiene en el tRABAjo}

La informalización del trabajo no se refiere tan solo al incumplimiento de la legislación laboral y fiscal, sino también al de las normativas sanitarias y de higiene básicas (locales reducidos y sin ventilación, fuertes olores por el uso de pegamentos y de material químico,...). En el caso de los talleres clandestinos, el incumplimiento de la normativa sanitaria y de higiene no persigue solo una reducción de los costes laborales sino que es también una consecuencia de su necesidad de protegerse de posibles inspecciones. Esto ha provocado la siniestra paradoja de que la ciudad que es reconocida a nivel nacional como la ciudad del calzado se encuentre llena de talleres "fantasmas" sin carteles en sus puertas, sin ventilaciones adecuadas y con trabajadores en la sombra, algo a lo que Benton (1990) se refirió como "fábricas invisibles".

En el caso de los talleres legales, el incumplimiento de las normas sanitarias (principalmente de ventilaciones insuficientes) se debe a que los locales donde se realiza la actividad suelen ser pequeños, con todo el espacio ocupado por máquinas y poco ventilados. Un entrevistada relata las difíciles condiciones de trabajo de su marido: 
“... con dos máquinas a más de 40 grados y encima con una ventana así de pequeñita que no entra aire ni nada". (Mujer, 47 años, aparadora).

La preferencia por este tipo de locales radica en la incapacidad de asumir los costes de espacios más amplios (Sassen 2007).

\section{CONTROL EMPRESARIAL Y NEGOCIACIÓN COLECTIVA}

En un contexto productivo en el que se combina un marco regulativo de las relaciones laborales crecientemente desregulado, unas prácticas de economía sumergida y una fragmentación del tejido productivo en pequeñas empresas de régimen familiar, el poder de negociación de los diferentes actores está desigualmente distribuido. Empresarios e intermediarios poseen mayor capacidad de negociación que los trabajadores, lo cual supone que es muy complicado para los trabajadores establecer límites a la gestión laboral de los empresarios e intermediarios. En la norma salarial de empleo la legislación imponía límites al poder de decisión empresarial con respecto a la gestión de la producción y de las relaciones laborales (Prieto 2002). En este sector apenas pueden distinguirse límites más que el de la resistencia físico-corporal de los trabajadores y los que se autoimpongan empresarios e intermediarios. Esta ampliación del poder sobre el trabajo ha intensificado las formas de control sobre los trabajadores. En este sentido, Benton (1990) señaló que la mayor ventaja de la informalización no radicaba en la reducción neta de los costes laborales y en el aumento de la productividad sino, sobre todo, en el incremento del control sobre los trabajadores. De hecho, en los últimos años, los cierres falsos de empresas parecen haberse convertido en un instrumento de resolución unilateral de conflictos y en un medio disciplinario para los trabajadores. No solo es que un trabajador pueda carecer de contrato o que se impongan unilateralmente salarios y condiciones, sino que en el siguiente cierre puede no ser contratado si su actitud es conflictiva. Todo ello supone un grave deterioro del poder de negociación de los trabajadores:

“... Aprovechan para depurar. Los 'toca-huevos' se van quedando atrás". (Grupo hombres jóvenes trabajadores del calzado).

Por otra parte, la estructura de la negociación colectiva en un entorno muy familiar y poco sindicalizado es muy frágil; por tanto, suele haber pocos representantes sindicales, y cuando existen, suelen elegirse los familiares o gente de confianza. Como señalan los informantes entrevistados, los convenios se incumplen permanentemente; la presencia de sindicatos en las empresas se hace imposible sin estabilidad laboral (como vimos, tan solo un 10-12\% tendrían contratos fijos), ya que el número de representantes de los trabajadores se establece según el número de empleados, y los trabajadores sin contrato no cuentan. Por otro lado, los trabajadores temporales (la mayoría con contratos meno- 
res de 6 meses) difícilmente pueden atreverse a negociar porque serían despedidos 0 no renovados.

Además, suele recurrirse poco al derecho de denuncia ante la inspección de trabajo debido a que se exige la identificación del denunciante. En un entorno local, esto supone que el denunciante puede ser inmediatamente identificado y despedido. Las denuncias, hechas para proteger el estatuto del trabajador con derechos, supondrían para la empresa el cumplimiento de la normativa legal y el hecho de hacer frente a una multa. El denunciante podría beneficiarse, pero lo más probable es que fuera despedido.

En estas circunstancias está comenzando a ser habitual enviar anónimos (mediante correos electrónicos, notas...), poniendo en conocimiento de los sindicatos los nombres y ubicación de las empresas donde se producen irregularidades (por ejemplo, en aquellas donde la totalidad de los trabajadores están sin contrato) para que los sindicatos actúen mediante denuncia ante Inspección de Trabajo. En la mayoría de las ocasiones, cuando se presenta la inspección, solo el trabajador que ha alertado de la situación dice la verdad y el resto mienten sobre su antigüedad en la empresa, por temor a ser despedidos. Es habitual que procedan a dar de alta a todos los trabajadores de manera inmediata y que a los pocos días se resuelva el expediente. El trabajador que ha denunciado o que no ha mentido será despedido, o bien no será contratado en el próximo cierre, o bien se le degradará:

"Después de 11 años en la máquina cortando nos pusieron a la mesa. Yo lo entiendo como castigo". (Hombre, 53 años, trabajador del calzado).

En otras ocasiones la persona ya ha sido despedida y necesita que sus compañeros testifiquen, hecho que difícilmente conseguirá por el temor a correr la misma suerte. En estas ocasiones acuden a los sindicatos o a gabinetes jurídicos para que les acompañen y asesoren en el juicio, donde tratarán de encontrar pruebas que puedan justificar su relación contractual. En otras ocasiones el trabajador necesita justificar sus años de trabajo para poder tener derecho a la jubilación. Y, de nuevo, el juicio y las pruebas (cartillas del banco guardadas durante mucho años, testigos de que lo han visto en la empresa, etc.).

En definitiva, la temporalidad de los contratos y la informalización de las relaciones laborales dificultan que se desarrollen mecanismos de negociación colectiva, de ahí que predomine la gestión individualizada de los conflictos, situación en la que el poder de negociación de los trabajadores es muy débil.

\section{Protección Social y Económica}

Las condiciones de informalidad y la temporalidad del empleo no solo suponen en sí mismas un menoscabo de los derechos laborales, sino que además dificultan el acceso de los trabajadores a la gama de servicios públicos provistos por las redes estatales. Se trata de los servicios sanitarios, de desempleo, jubilación, acceso a vivienda, guarderías, comedor 
escolar, etc., que trascendían la relación laboral y que daban grosor a la condición de ciudadanía social en la medida en que eran considerados como derechos sociales y económicos.

La prestación por desempleo y la jubilación constituyen sin lugar a dudas los dos derechos socioeconómicos que más preocupan a los trabajadores del calzado en Elda. Para cobrar la prestación por desempleo es necesario trabajar al menos un año para tener derecho a una prestación de cuatro meses con el $70 \%$ del salario. En un contexto en el que prácticamente nadie trabaja un año completo, debido a la estacionalidad de la actividad y a la estrategia de rotación de contratos temporales, es habitual que los trabajadores accedan al cobro de la prestación cada dos o tres años. Por otra parte, dada la práctica generalizada de pagar una parte del salario de manera extraoficial, la cuantía de la prestación suele ser muy baja. En resumen, las prestaciones por desempleo a las que tienen acceso los trabajadores son más espaciadas en el tiempo, de menor cuantía y de menor duración. La consecuencia es que los trabajadores son cada vez más dependientes de las redes informales de empleo del sector, a pesar de que en ocasiones puedan combinar la remuneración de la prestación con la del salario.

En cuanto a la jubilación, para acceder a la pensión es necesario haber cotizado durante al menos 15 años. Por otra parte, la cuantía se calcula haciendo la media de las bases de cotización de los últimos 15 años $^{11}$. Al igual que en el caso de las prestaciones por desempleo, la constante alternancia de periodos de actividad y de inactividad, acompañada de unas bases de cotización muy bajas hacen que el cobro de la pensión resulte muy complicado. Como efecto de esto algunos trabajadores mayores de 65 años se ven obligados a prolongar su periodo de actividad para alcanzar el periodo mínimo de cotización, en ocasiones pagando ellos mismos la parte empresarial de las cotizaciones a la seguridad social a través de un convenio especial individual, o recurriendo a "favores personales":

"Claro ese jefe se lo hizo a mi madre, hay quienes no te lo hacen, pero es porque a ellos les conviene, porque cuando tú metes a una mujer de más de 45 años, te dan una subvención, o sea a él le están dando la subvención y tú le estás pagando el dinero sin cobrar nada, sino pagando". (Mujer, 47 años, aparadora).

Una prolongación de la edad real de jubilación que también se debe a la necesidad de encontrar una ocupación para complementar la exigua pensión que les queda tras años de cotización intermitente y a la baja.

"Y ayer me llamó [su madre] y me dijo que a la vecina le ha dado un derrame o algo, y ya le dije, que a lo mejor así deja de aparar, porque con '83 años' ya está bien”. (Mujer, 30 años, profesional. Entrecomillado añadido).

\footnotetext{
${ }^{11}$ La última reforma de la Seguridad Social que entró en vigor en 2013 ha endurecido las condiciones de acceso y el procedimiento de cálculo.
} 


\section{CONCLUSIONES}

Este artículo ha tratado de dar cuenta de la norma informal de empleo que se ha constituido en la industria eldense del calzado, así como del debilitamiento de la condición de ciudadanía asociada a ella.

Desde los años ochenta esta estrategia basada en la informalidad se ha convertido en algo estructural. Tanto en el ciclo de crecimiento, desde mediados de los ochenta y hasta el año 2000, como en el ciclo recesivo iniciado en ese mismo año y que se ha acentuado desde 2008, la degradación del trabajo ha sido persistente. Los informantes han dado cuenta de ello al referirse a su inestable situación contractual, a la pronunciada estacionalidad de la actividad, a las menguantes remuneraciones, al creciente control empresarial, a las dificultades para reivindicar individual o colectivamente sus intereses, y a la pérdida efectiva de algunos derechos sociales y económicos que ya han sufrido.

Como se ha indicado anteriormente, la informalidad y la temporalidad del empleo en el sector del calzado no solo son en sí mismos la manifestación del deterioro de los derechos laborales, sino que además limitan el acceso a otro tipo de derechos socioeconómicos (prestación por desempleo, jubilación y sanidad; entre otros) que apuntalan la condición de ciudadanía. Lo más llamativo y singular de las condiciones de trabajo del sector es que la informalidad ha adquirido una naturaleza estructural y ha alcanzado unas dimensiones colosales. No hay aspecto de las relaciones laborales que haya quedado al margen de la informalidad: tipos de contratación, estructura del salario, organización de la jornada, derechos sociales y económicos.

La informalización del empleo en el sector del calzado puede interpretarse como una vuelta de tuerca más en la actual tendencia hacia la "desdemocratización" del trabajo, lo que indica, no tanto una despolitización del trabajo sino, más bien, una creciente subordinación de la condición política de los trabajadores, su ciudadanía, a las necesidades de flexibilidad y movilidad del mercado de trabajo.

Esta situación queda gráficamente descrita por la doble paradoja de la ciudadanía laboral (Alonso 2007). A pesar de que la participación en el mercado de trabajo es cada vez mayor y más intensa a nivel global, no se ha producido un mayor protagonismo político de los trabajadores sino más bien todo lo contrario, ha aumentado su dependencia económica y política con respecto a los empresarios; algo que ha de interpretarse como una clara ruptura del pacto keynesiano, por la que se pierde la escasa capacidad de control democrático que los trabajadores conservaban sobre las condiciones de mercantilización de su mano de obra.

Por otro lado, la segunda paradoja está relacionada con las fuentes de la ciudadanía. La ciudadanía social era una ciudadanía laboral en el sentido de que el acceso al conjunto de los derechos sociales se basaba en el vínculo formal con el trabajo asalariado. Este enfoque se ha criticado desde diferentes perspectivas, entre otras: feministas, étnicas, ecológicas. Estas críticas suponían la apertura de un interesante debate acerca de qué es lo que nos convierte en ciudadanos y cuál es la extensión social de los derechos. 
A pesar de todas estas críticas, la participación en el mercado de trabajo sigue siendo considerada el vehículo privilegiado para alcanzar un reconocimiento mínimo de derechos políticos, sociales y económicos, aunque, como se ha podido comprobar también en el caso de Elda, la participación en el trabajo asalariado genera hoy día cada vez menos derechos.

Y es precisamente esto lo que llama poderosamente la atención. El proceso de remercantilización de la sociedad, no solo ha debilitado el vínculo entre el trabajo y la ciudadanía sino que, más importante aún, parece haber erosionado la legitimidad de cualquier institución social que pretenda invertir la relación de subordinación de lo político (de las instituciones políticas depositarias de la soberanía popular) y de todas las instituciones no económicas con respecto a lo económico.

¿Es Elda, por tanto, el futuro de los países del sur de Europa? Desde 2009 los países europeos, especialmente los del sur, son llamados a realizar reformas estructurales y a contener el déficit público puesto que, según la ortodoxia económica, ese es el único camino para alcanzar la senda del crecimiento y crear empleo. Este modelo se basa en una devaluación de los costes salariales y de los costes sociales como forma de mejorar la competitividad y la capacidad exportadora de la economía en los mercados globales. Por medio de la informalización, el sector del calzado en Elda ha alcanzado de facto, en materia laboral, todo aquello que se exige ahora al conjunto de los países del sur de Europa. El radical proceso de informalización que ha tenido lugar en Elda desde finales de los setenta ha supuesto, por tanto, una verdadera estrategia de devaluación competitiva al eliminar todo aquello que ahora, desde la ortodoxia económica, es considerado como un obstáculo para la competitividad: derechos laborales, derechos sociales, etc.

\section{REFERENCIAS BibLIOgRÁfICAS}

Alonso, L. E. 2007. La crisis de la ciudadanía laboral. Barcelona: Anthropos.

Alonso, L. E. 1999. Trabajo y ciudadanía: estudios sobre la crisis de la sociedad salarial. Madrid: Trotta.

Aragón, J. 2012. Las reformas laborales en España y su repercusión en materia de empleo. 52 reformas desde la aprobación del estatuto de los trabajadores en 1980. Madrid: Fundación 1 de mayo.

Arnal, M., C. de Castro, A. Lahera-Sánchez, J. C. Revilla y F. J. Tovar. 2012. "Two Spanish Cities at the Crossroads: Changing Identities in Elda and Alcoy". Pp. 91-123 en Changing Work and Community Identities in European Regions, editado por Kirk, J., S. Contrepois and S. Jefferys. Londres: Palgrave Macmillan.

Benton, L. 1990. Invisible factories: the informal economy and industrial development in Spain. Albany: State University of New York.

Bosch, G., S. Lehndorff and J. Rubery. 2009. European employment models in flux. Basingstoke: Palgrave Macmillan. 
Cachón, L. 2005. Bases sociales de los sucesos de Elche de septiembre de 2004: crisis industrial, inmigración y xenofobia. Madrid: Ministerio de Trabajo y Asuntos Sociales.

Davis-Blake, A. y J. P. Broschak. 2009. "Outsourcing and the Changing Nature of Work". Annual Review of Sociology 35: 321-340.

Doogan, K. 2009. New capitalism?: The transformation of work. Londres: Polity.

Federación de Industrias del Calzado Español. 2011. El sector del calzado. Informe anual 2008; 2009; 2010; 2011. Madrid: Federación de Industrias del Calzado Español.

Fevre, R. 2007. "Employment insecurity and social theory: the power of nightmares". Work, Employment \& Society 21: 517-535.

Harvey, D. 2007. Breve historia del neoliberalismo. Madrid: Akal.

Ingham, G. 2010. Capitalismo. Madrid: Alianza Editorial.

Koch, M. 2006. Roads to post-Fordism: labour markets and social structures in Europe. Aldershot: Ashgate.

Miguélez, F. y C. Prieto. 2009. "Trasformaciones del empleo, flexibilidad y relaciones laborales en Europa". Política y sociedad 46: 275-287.

Mingione, E. 1994. Las sociedades fragmentadas: una sociología de la vida económica más allá del paradigma del mercado. Madrid: Ministerio de Trabajo y Seguridad Social.

Miranda, J. A. 2001. "En busca del tiempo perdido: la conquista del mercado exterior y el desarrollo de la industria del calzado en España en la segunda mitad del siglo XX". Revista de Historia Industrial 19: 165-203.

Nash, J. 1989. From tank town to high tech: the clash of community and industrial cycles. New York: State University of New York Press.

Pisarello, G. 2011. Un largo Termidor. La ofensiva del constitucionalismo antidemocrático. Madrid: Trotta.

Portes, A., M. Castells y L. A. Benton. 1989. The informal economy: studies in advanced and less developed countries. Baltimore. Londres: Johns Hopkins University Press.

Portes, A. y W. Haller. 2005. "The informal economy". Pp. 403-428 en The handbook of economic sociology. 2nd edition, editado por N. J. Smelser and R. Swedberg. Princeton, Nueva York: Princeton University Press / Russell Sage Foundation.

Prieto, C. 2002. "La degradación del empleo o la norma social del empleo flexibilizado". Sistema 168: 89-106.

San Miguel, B. 2000. Elche, la fábrica dispersa los trabajadores de la industria del calzado, cambios en las condiciones de vida y trabajo. Alicante: Instituto Alicantino de Cultura Juan Gil Albert.

San Miguel, B. 2001. Zapatos de cristal: la mujer como protagonista en la industria valenciana del calzado. Valencia: Confederación Sindical CC. OO.-PV.

Sassen, S. 2007. Una sociología de la globalización. Buenos Aires: Katz.

Standing, G. 2009. Work after globalisation. Building occupational citizenship. Cheltenham, UK: Edward Elgar. 
Stewart, P., M. Richardson, A. Danford, K. Murphy, T. Richardson y V. Wass. 2009. We sell our time no more: workers' struggles against lean production in the British car industry. Londres y Nueva York: Pluto.

Tilly, C. 2010. Democracia. Madrid: Akal.

Valero, J. R. 1992. Elda, 1832-1980: industria del calzado y transformación social. Alicante: Instituto de Cultura Juan Gil Albert.

Ybarra, J. 2000. "La informalización como estrategia productiva. Un análisis del calzado valenciano". Revista de Estudios Regionales 57: 199-220.

Ybarra, J., J. M. Giner Pérez, M. J. Santa María Beneyto y Universitat d'Alacant. 2002. El Calzado en España: del sector al territorio. Alicante: Universidad de Alicante.

Ybarra, J., B. San Miguel, J. Hurtado y M. J. Santa María. 2004. El calzado en el Vinalopó: entre la continuidad y la ruptura. Estudio sobre economía y trabajo en el sector. Alicante: Instituto de desarrollo de Elda (Idelsa), Ayuntamiento de Elda y Ayuntamiento de Petrer.

Carlos de Castro Pericacho es Profesor del departamento de sociología de la Universidad Autónoma de Madrid. Sus investigaciones se centran en el estudio de los procesos políticos de formación de contextos productivos en la economía global y en el estudio de los procesos individuales y colectivos de formación de subjetividades. Recientemente ha sido coautor de: "Labour, Gender and Political Conflicts in the Global Agri-food System. The case of Agri-export model of Murcia, Spain" en Bonanno, A. y Salete Cavalcanti, J. (eds) Labor Relations in a Globalized Food, Emerald, 2014.

María Arnal Sarasa es Doctora en Sociología y profesora de la Universidad Complutense de Madrid. Miembro del equipo EGECO (Empleo, género y regímenes de cohesión social). Sus líneas de investigación son: empleo, nuevos pobres y migraciones.

Arturo Lahera Sánchez es Profesor Titular de Sociología del Trabajo y Ergonomía en la Universidad Complutense de Madrid. Sus investigaciones se centran en el análisis de la innovación tecnológica en los procesos productivos y en el estudio de la emergencia de nuevos modelos industriales, así como en las áreas de organización del trabajo, estudios organizativos y patrimonio industrial.

\section{RECIBIDO: 05/11/2012}

ACEPTADO: 20/09/2013

PUBLICADO ONLINE: 21/07/2014 